\title{
OS MOVIMENTOS SOCIAIS DA AMÉRICA LATINA EM QUESTÃO ${ }^{1}$
}

Andréia Galvão

\begin{abstract}
Resumo
Este artigo se propõe a analisar a composição social, a plataforma reivindicativa e a forma de atuação de alguns movimentos sociais que eclodiram na cena política latino-americana no período recente. Esses movimentos foram escolhidos devido à sua dimensão política: todos eles possuem, cada um à sua maneira, um projeto político e produzem impactos políticos. Apesar da diversidade de projetos e dos diferentes impactos produzidos, e a despeito da heterogeneidade da base social mobilizada em cada movimento, o artigo busca apontar os elementos comuns e a possibilidade de encontrar uma unidade nos distintos movimentos. Essa unidade é pensada a partir de sua ideologia antineoliberal e do conceito de classes trabalhadoras.
\end{abstract}

Palavras-chave: Movimento social; Neoliberalismo; Classes Trabalhadoras.

\section{Abstract}

This article proposes to analyse the social composition, platform of demands, and the form of action taken by certain social movements that have appeared recently on the Latin-American political scene. These movements were chosen because of their political dimension: all have, in their own way, a political project and produce political impacts. Even with the diversity of projects and the different impacts produced, and despite the heterogeneity of the social base mobilized in each movement, this article seeks to point out the common elements and the possibility of finding a unity in distinct movements. This unity is thought of from its anti-neoliberal ideology and from the concept of the working classes.

Key-words: Social Movement; Neoliberalism; Working Classes.

\section{Introdução}

Nos anos 90, diferentes movimentos sociais eclodem na cena política latino-americana. Alguns deles não são exatamente novos, mas é nesse momento que se tornam mais expressivos, tornando-se conhecidos para além das fronteiras de seus países de origem. São movimentos rurais, como o MST (Movimento dos Trabalhadores Rurais Sem-Terra) no Brasil; urbanos, como os piqueteiros na Argentina; de caráter étnico, como os movimentos indígenas na Bolívia, Peru, Equador e México.

\footnotetext{
${ }^{1}$ Este artigo foi elaborado a partir das discussões do grupo de pesquisa Neoliberalismo e classes sociais, vinculado ao Cemarx/Unicamp, ao qual sou grata. Entretanto, sempre é bom lembrar que os problemas presentes neste texto são de minha inteira responsabilidade.
} 
A presente comunicação não se propõe a analisar cada um desses movimentos isoladamente, pois para isso seria necessário levar em consideração suas especificidades, bem como o contexto histórico particular dos países em que se desenvolvem. Ou seja, seria preciso discutir sua origem, sua inserção na cena política nacional e sua relação com outros movimentos e instituições políticas, a exemplo de partidos e sindicatos. Antes, pretendemos refletir sobre eles de modo conjunto, apontando seus elementos comuns.

Essa reflexão - que toma por base a bibliografia disponível - leva em conta os seguintes aspectos: a composição social, a plataforma reivindicativa e a forma de atuação desses movimentos. Para tanto, parte de algumas questões e de algumas hipóteses:

1) Que condições teriam possibilitado a constituição e a ascensão desses movimentos? A hipótese presente na maior parte da bibliografia sustenta que esses diferentes movimentos, a despeito de sua heterogeneidade, constituem uma resposta aos efeitos nefastos da política neoliberal que vem sendo implantada, desde os anos 1970 (se levada em conta a experiência do Chile) por diferentes governos da região.

2) Que tipo de relação esses movimentos estabelecem com a esfera política? Essa questão contém em si mesma um suposto, qual seja, o de que esses movimentos possuem uma dimensão política, dimensão essa que pode ser observada por dois ângulos: de um lado, porque se constituem em contraposição a instituições, projetos e medidas políticas; de outro, porque ao resistirem a essas instituições, projetos e medidas produzem um impacto político de monta. Esse impacto político passa pela criação de novas forças políticas; por sua posição - de oposição ou apoio - frente aos governos; por sua relação com os partidos políticos e com os demais movimentos sociais, como o sindical; pela luta por uma inserção institucional ou pela recusa a ela².

\footnotetext{
2 Não se trata, portanto, de pensar a autonomia como ausência de vínculos com as instituições políticas, sejam elas Estado, governos ou partidos, ao contrário do que propugna a bibliografia produzida sob a influência da teoria dos novos movimentos sociais (ver TATAGIBA, 2008). Diferentemente do que defendem os autores ligados a essa corrente, os movimentos sociais não têm propósitos meramente culturais, de transformação da sociedade civil, mas também políticos, mesmo que a tomada do poder
} 
3) Como definir esses movimentos? Esses movimentos caracterizam-se pela luta por direitos econômicos, como acesso à terra, garantia de trabalho ou benefícios sociais; e políticos, como o direito à participação política. Não se trata de lutar somente pelo reconhecimento de identidades étnicas ou de minorias, pois as reivindicações vão além dessas questões. Também não se trata de novos movimentos sociais stricto senso, não apenas porque alguns desses movimentos não são tão novos assim ${ }^{3}$, mas porque também não constituem necessariamente uma oposição ao movimento operário e sindical, mas se associam a ele, de formas distintas. Além disso, ao contrário do que propugnam as teorias sobre os novos movimentos sociais, é possível encontrar um caráter de classe nesses movimentos ${ }^{4}$, o que permite pensar sua unidade, a despeito de sua heterogeneidade.

\section{A relação entre neoliberalismo e movimentos sociais}

As causas que se encontram na origem desses diversos movimentos sociais são múltiplas, mas é possível encontrar, em todos eles, um aspecto comum: eles constituem uma reação ao neoliberalismo, muito embora a política neoliberal se apresente sob formas distintas e tenha sido aplicada com intensidade variada nos países latino-americanos. A Argentina talvez tenha sido o caso mais exemplar de uma política neoliberal levada ao extremo, cujo colapso teve um efeito devastador, dando origem à crise de 2001. A crise

de Estado não esteja em questão. Daí a necessidade de se distinguir as diferentes formas de luta política. Nesse sentido, também se destaca a contribuição de Tarrow (1994), para quem os movimentos sociais são influenciados pelo sistema político, bem como buscam exercer influência sobre ele. Isto posto, seria interessante analisar seu impacto sobre a nova configuração política da América Latina, mediante a eleição dos diferentes governos de esquerdas.

${ }^{3} \mathrm{O}$ campesinato é um velho sujeito social, que alguns autores, inclusive marxistas, com a disseminação das relações de produção capitalista no campo, consideraram que estivesse fadado ao desaparecimento (por se tratar de uma classe não central no modo de produção capitalista). Aqui, é importante destacar a importância do movimento camponês na Revolução Russa de 1905, na Revolução Mexicana (1910-20), na Revolução Boliviana (1952), as Ligas Camponesas no Brasil (1954-64). O mesmo se pode dizer dos indígenas, cujos levantes em prol da reconstrução da nação andina marcaram a Bolívia e o Peru no século XVIII.

4 Sobre reconhecimento, ver a polêmica entre Honneth (2003) e Frazer (2001). Sobre novos movimentos sociais, consultar: Melucci (1980), Offe (1985) e Touraine (1985). Sobre a relação entre classes e movimentos sociais, Eder (2001), Sallum Jr. (2005). 
financeira provocada pela paridade peso/dólar deu origem ao corralito (retenção de dinheiro nos bancos, mediante o estabelecimento de um limite semanal de retirada) e provocou a explosão do desemprego e um empobrecimento generalizado. Essa conjuntura deu origem a movimentos distintos, cuja unidade pode ser encontrada no questionamento do neoliberalismo. São movimentos que reagem ao desemprego, à precarização e à pobreza, exprimindo o descontentamento com as falsas promessas do neoliberalismo e com o slogan da modernidade: compreendem o panelaço da classe média contra o corralito, os piquetes dos desempregados, o movimento das fábricas recuperadas e as assembléias de bairro (CHESNAIS e DIVÈS, 2002; PALOMINO, 2006).

Isso indica que o impacto negativo do neoliberalismo afetou não apenas a classe operária, mas também as classes médias e até "grupos de burguesia dependente vinculados ao mercado interno" (QUIJANO, 2004, p. 75), produzindo uma contínua e crescente polarização social da população: "As três décadas de neoliberalismo na América Latina criaram as condições, as necessidades e os sujeitos sociais de um horizonte de conflitos sociais e políticos" (QUIJANO, 2004, p. 82). Evidentemente, as maneiras pelas quais o neoliberalismo afeta as diferentes classes e frações são diferentes.

Esses movimentos denunciam os tratados de livre comércio, a ingerência dos organismos multilaterais sobre as políticas governamentais, declaram-se antiimperialistas ${ }^{5}$, criticam o capitalismo neoliberal, defendem Estados plurinacionais que reconheçam sua autodeterminação e seus direitos coletivos, demandam a participação em assembléias constituintes, cujos representantes não seriam escolhidos "via partidos ou eleições tradicionais" (ALMEIDA, 2006/7, p. 75).

O caso mexicano produziu movimentos significativos, como os zapatistas de Chiapas e os manifestantes de Oaxaca. O primeiro tornouse mundialmente conhecido a partir do levante de $1^{\circ}$ de janeiro de 1994,

${ }^{5} \mathrm{E}$ alguns deles anti-capitalistas, embora esse elemento faça mais parte do discurso do que da prática política dos movimentos. 
quando os zapatistas se insurgiram contra a entrada em vigor do Tratado de Livre Comércio da América do Norte (Nafta). Trata-se de uma luta pelo resgate da identidade e da autonomia, pela dignidade, que passa pela "recuperação e defesa da cultura, do fortalecimento da luta pelos direitos humanos individuais e coletivos, assim como pela geração de novas formas democráticas de participação nos assuntos públicos" (GÁNDARA, 2004, p. 104). Os segundos tornaram-se conhecidos em 2006, a partir de um movimento desencadeado por associações de professores em greve por aumento de salário e melhorias no sistema educativo. Esse movimento também exprime uma reação ao governo corrompido do PRI (Partido Revolucionário Institucional) (mais particularmente, à eleição fraudulenta de Ulyses Ruiz ao cargo de governador em 2004) e à deterioração das condições de vida da população: 2/3 da população daquele estado é indígena, 3/4 vive na pobreza, sendo que a situação sócio-econômica foi agravada pelo Nafta, que piorou as condições de vida no campo, levando à migração. Também as mudanças constitucionais promovidas pelo governo Salinas de Gortari, possibilitando a divisão e venda das terras comunais, produziram forte impacto num Estado onde $85 \%$ do território é de propriedade comunal, ao levar à remercantilização das terras e ao fim dos ejidos. Esses antecedentes mais amplos levaram ao apoio ao movimento dos professores e à ampliação de suas demandas, que passa de uma ação corporativa (greve dos professores) à luta pela destituição do governador (GOGOL, 2007).

A relação entre neoliberalismo e movimentos sociais também é evidente no caso boliviano: a Marcha Indígena pelo Território e a Dignidade, de 1990, constitui uma reação às políticas de ajuste estrutural que passaram a ser aplicadas em 1985 (com a eleição de Victor Paz Estenssoro) e que se chocavam com as autonomias departamentais, já que pretendiam restaurar a autoridade e a unidade do Estado (REGALSKY, 2007), e com as autonomias indígenas, como a justiça comunitária. O ciclo de protestos, que envolveu organizações sindicais indígenas e de bairro e provocou a queda dos presidentes Gonzalo Sánchez de Lozada e Carlos Mesa, rechaçava os efeitos da 
política neoliberal, como "o aumento das tarifas dos serviços públicos (principalmente a água) e a desnacionalização da economia [que resultou no] (controle transnacional dos hidrocarburetos)" (STEFANONI, 2007, p. 54). A privatização das minas estatais contribuiu para fortalecer o movimento camponês e para sua articulação com o movimento sindical, já que mineiros se tornaram camponeses após terem sido "desalojados das minas estatais que foram privatizadas entre 1985 e 1988" (SANJINÉS, 2004, p. 210). Também contribuiu para reativar o nacionalismo indígena, contra as transnacionais que adquiriram as empresas privatizadas (DO ALTO, 2007).

A guerra da água, de Cochabamba (2000), contra a privatização do serviço municipal de água (Consórcio Águas Del Tunari), que provocou o aumento do preço da água e também assegurou à empresa o controle sobre os sistemas de irrigação e poços administrados pelas próprias comunidades camponesas; os bloqueios aymaras em La Paz, em 2000 e 2001; e as guerras do gás, em 2003 e 2005, contra um consórcio transnacional de exportação do gás para a América do Norte, e em prol da nacionalização e reestatização dos hidrocarburetos e da convocação de uma Assembléia Constituinte, constituem os momentos mais expressivos desses movimentos ${ }^{6}$.

Esses exemplos indicam que esses movimentos exprimem uma crítica ao neoliberalismo e, ao mesmo tempo, sinalizam que as críticas e resistências à política neoliberal provocam mudanças e adaptações no neoliberalismo, contribuindo para deslegitimá-lo política e ideologicamente, bem como para modificar o cenário político, como se verifica por meio da eleição de partidos de centro-esquerda?.

\section{A composição social dos movimentos e as formas de luta}

Esses movimentos possuem uma abrangência social ampla, sendo possível apontar, em alguns casos, a múltipla condição dos

\footnotetext{
${ }^{6}$ Embora a Venezuela não esteja incluída entre os países mencionados neste trabalho, pode-se mencionar o Caracazo, de 1989, quando se registraram saques provocados pelo aumento generalizado do preço de produtos de primeira necessidade, após a eleição de Carlos Andres Perez.

${ }^{7}$ Não vamos aqui discutir a natureza dos governos comandados por esses partidos.
} 
mobilizados: no exemplo de Oaxaca, os mobilizados são, a um só tempo, indígenas, mulheres, jovens e trabalhadores urbanos (professores) (GOGOL, 2007).

Essa múltipla condição indica que, para além dos pertencimentos de ordem étnica, de gênero, geracional, é possível identificar um caráter de classe nesses movimentos. Essa intersecção entre identidade étnica e de classe também é visível no caso boliviano, tanto no caso do sindicalismo mineiro (operários), quanto dos camponeses produtores de coca:

O processo de demanda de reconhecimento identitário começou a se ligar às reivindicações camponesas e de classe, à demanda pela terra e pelo território e, pouco a pouco, à luta pelo controle dos recursos naturais [...] a Guerra pela Água [2000] como confluência dos movimentos urbanos com os camponeses (REGALSKY, 2007, p. 56).

Assim, a luta é, a um só tempo, contra a opressão econômica, de um lado, e contra a opressão sócio-cultural (provocada pela condição indígena), de outro (DO ALTO, 2007, p. 88).

As convergências entre trabalhadores de categorias ou universos distintos (no caso boliviano, urbanos e rurais; no caso dos zapatistas, a confluência entre guerrilheiros revolucionários e indígenas), ocorrem em outras experiências: no caso argentino, verifica-se a confluência entre trabalhadores (assalariados entram em greve para obter o pagamento de salários), desempregados (sobretudo operários) e classe média, que passa por um processo de pauperização (QUIJANO, 2004; CHESNAIS e DIVÈs, 2002).

No caso brasileiro, a composição social do MST inclui desempregados urbanos e trabalhadores informais, bem como camponeses expulsos de suas terras. Com efeito, a política neoliberal bloqueia as possibilidades de acomodar os ex-camponeses e assalariados rurais nas cidades. Impossibilitados de encontrar um emprego, mesmo que no setor informal, estes se juntam ao MST. O mesmo acontece com os desempregados urbanos, ao verem negadas as 
oportunidades de se reintegrar à empresa ou de serem requalificados e transferidos a uma outra ocupação. Nesse sentido, as conseqüências das políticas neoliberais, no campo e nas cidades acabam fornecendo uma base social para a expansão do MST (COLETTI, 2002).

Esses movimentos, tão diversos em sua composição social e em suas demandas, também se diferenciam em termos de correntes e tendências político-ideológicas, bem como em suas formas de atuação. Estas são condicionadas pelas tradições locais, de modo que não há características únicas. Por exemplo, os países com forte presença indígena são marcados por experiências coletivistas e comunitárias; os países mais industrializados, com um proletariado urbano mais expressivo, são marcados pela experiência do movimento sindical e por suas relações com os partidos políticos e com o Estado, a exemplo do corporativismo no México, no Brasil e na Argentina.

O caso argentino deve ser compreendido à luz da tradição peronista: os piqueteiros expressam a ruptura com os sindicatos peronistas, bem como a rejeição ao sistema político e aos partidos tradicionais. O MST brasileiro se constitui em oposição à Contag, Confederação dos Trabalhadores Agrícolas, inserida na estrutura sindical corporativa. No México, tanto os zapatistas quanto a comuna de Oaxaca se insurgem contra o monopólio do PRI, evidenciado nos 70 anos de domínio desse partido.

Os movimentos latino-americanos se originam ou se amplificam num contexto de crise da democracia representativa, cuja expressão são os limites à participação popular (decorrentes de sistemas políticos excludentes) e a degeneração de instituições políticas tradicionais (partidos e sindicatos marcados pela corrupção, por práticas autoritárias e pela incapacidade de representar as demandas sociais que emergem nesse novo contexto histórico). Sua constituição desafia o espaço institucionalizado da política tradicional, fazendo frente à crise de representação, recusando a democracia delegativa e buscando novas formas de participação. Essas formas de participação passam pela constituição de organismos sem inserção no sistema político tradicional, a exemplo das assembléias de bairros na Argentina, da Assembléia 
Popular dos Povos de Oaxaca (APPO), dos municípios autônomos de Chiapas, que constituem uma espécie de duplo poder, na medida em que as autoridades territoriais constituem-se paralelamente ao Estado central e gozam de autonomia, já que controlam, através de assembléias comunitárias e autoridades tradicionais ou sindicais, o que ocorre em seu espaço territorial (REGALSKY, 2007) ${ }^{8}$.

Além de experiências de democracia direta, as formas de luta incluem práticas de autogestão (no caso das fábricas recuperadas) e ações de solidariedade, dentre as quais se destacam os clubes de troca (espaços destinados à troca de bens e serviços, que têm moeda própria: o crédito social), merenderos e comedores da Argentina. Também é possível encontrar mecanismos historicamente empregados pelo movimento operário, como barricadas, piquetes e ocupação de fábricas, acrescidos dos bloqueios de estrada promovidos por mineiros e camponeses, dos saques promovidos pelos desempregados, dos panelaços da classe média, da ocupação de terras pelos sem-terra. Algumas experiências valem-se habilmente dos meios de comunicação, como o rádio e a própria internet, para difundir suas bandeiras de luta para além de suas fronteiras, a exemplo do caso mexicano (tanto em Oaxaca como em Chiapas) e ainda assumem um perfil militarizado, como o Exército Zapatista de Libertação Nacional (EZLN).

Alguns movimentos surgem espontaneamente, por fora de estruturas institucionais e partidos políticos tradicionais e até mesmo sem a mediação de sindicatos, como os movimentos de desempregados, das fábricas recuperadas e as assembléias de bairro argentinas. As jornadas de 19 e 20 de dezembro de 2001, que culminaram na queda do presidente Fernando De la Rúa e na adoção do lema que se vayan todos, caracterizou-se pela ausência de organizações de trabalhadores, salvo os de extrema esquerda. Estes, todavia, não dirigiram o movimento, de modo que a participação se deu de maneira individual e não organizada (PALOMINO, 2006). Outros movimentos, embora

${ }^{8} \mathrm{O}$ debate bibliográfico referente a Chiapas tende a caracterizar essa experiência como uma tentativa de Mudar o mundo sem tomar o poder (HOLLOWAY, 2003). Elogiada por alguns, que apontam as virtudes da sociedade civil em contraposição aos defeitos do Estado, essa estratégia é criticada por outros, como Borón (2003), que a caracteriza como a antipolítica do zapatismo. 
contem com a participação de organizações de esquerda em seu processo de constituição, dão origem a outras forças políticas e espaços organizativos. Esse é o caso de algumas associações de piqueteiros na Argentina, do MST no Brasil, do Pachakutik no Equador ${ }^{9}$, do Movimento ao Socialismo (MAS) e do Movimento Indígena Pachacuti (MIP) na Bolívia, do EZLN em Chiapas.

\section{As reivindicações e suas implicações políticas}

É possível afirmar que esses movimentos, cujas singularidades estão relacionadas às experiências político-organizativas e à história pregressa dos países em que se desenvolvem, exprimem uma recusa às instituições políticas tradicionais, recusa essa que passa pela criação de novas forças políticas - ainda que a relação com organizações já existentes não esteja descartada. Aqui também é possível observar características diferenciadas quanto à participação nos espaços institucionalizados, já que, na maioria dos casos, verifica-se uma recusa a esse tipo de participação, muito embora a criação de novas forças políticas destine-se, por vezes, a assegurar essa participação por fora das organizações tradicionais.

Esse debate não pode ser traduzido em termos dicotômicos, numa polarização entre autonomia $X$ institucionalização. Todo movimento social cria instituições e/ou se relaciona com as instituições políticas existentes, ainda que o faça de formas e em graus variados. 0 que é central é a discussão sobre autonomia, para verificar se a relação com outras organizações e a participação nos espaços institucionalizados da política implica o abandono de sua plataforma reivindicativa e se

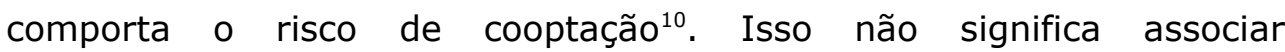
automaticamente participação e cooptação. A participação não é por si

\footnotetext{
9 Todavia, os indígenas que se sublevaram em 1990, organizados na Conaie, dialogaram diretamente com o Estado, sem a participação das principais instituições democráticas como os partidos políticos e o Congresso. A interlocução direta com o presidente, sem passar pelos mecanismos da democracia representativa, ocorre devido à exclusão dos indígenas do sistema político (DÁVALOS, 2004).

10 Ao mesmo tempo, convém destacar a necessidade de discutir os limites da luta meramente institucional (quando a via legal é a única opção ou a opção prioritária), que produz uma tendência à acomodação, ao conformismo, à integração, à ordem, ao respeito às regras do jogo. Pode-se lutar contra as instituições existentes, mas apenas para substituí-las, mantendo-se o arcabouço institucional e suas regras de funcionamento.
}

REVISTA DEBATES, Porto Alegre, v. 2, n. 2, p. 8-24, jul.-dez. 2008. 17 
só virtuosa, nem, de maneira oposta, a causa de todos os males. Por outro lado, a recusa à participação não é sinônimo de sectarismo e isolacionismo. É necessário avaliar a conjuntura em que ela se produz. Do mesmo modo, é necessário qualificar o que se entende por institucionalização. Ela compreende tanto a constituição de instituições (que tendem à burocratização à medida que se consolidam) quanto a participação em instituições já reconhecidas pelo sistema político. São dois processos independentes, ou seja, um não leva necessariamente ao outro.

Algumas experiências buscam constituir uma alternativa de poder - ainda que não necessariamente numa perspectiva anti-capitalista, mas de implementar mudanças na concepção de Estado, a fim de democratizá-lo e de mudar a estrutura econômica -; outras não se colocam a questão da tomada do poder, operando desde reivindicações ao Estado (como políticas públicas e benefícios sociais para assegurar sua subsistência imediata) até a constituição de territórios autônomos baseados em critérios étnicos, como no caso do zapatismo ${ }^{11}$.

Qualquer que seja o caso, esses movimentos contribuem para politizar a sociedade civil, ampliando as fronteiras da política e promovendo novas práticas. Desse modo, "apagam as fronteiras tradicionais entre política e sociedade", fazendo política "desde a sociedade" (PALOMINO, 2006, p. 310) e ampliando as fronteiras da cidadania. Assim, é possível afirmar que o caráter político é um elemento comum aos diferentes movimentos sociais. Apesar da diversidade de objetivos, a política é o fim último. Isso significa que

\footnotetext{
${ }^{11}$ O conflito social em Chiapas é multidimensional e multicausal. Tem uma dimensão nacional, ainda que relacionada à luta contra a globalização neoliberal; e política, ainda que não se proponha a tomar o poder. Suas demandas vão além das reivindicações de direitos indígenas (cuja incorporação está relacionada às carências e marginalização à que essa população foi historicamente submetida). Compreendem a luta pela transformação do Estado e da sociedade, por meio da constituição de estruturas de representação política e de exercício de governo alternativos (GÁNDARA, 2004). Assim, o zapatismo não busca tomar o poder central, mas constituir territórios autônomos em relação a ele. Esses territórios, administrados por instâncias próprias (os Caracoles), distintas das estruturas oficiais, contam também com seu próprio exército. Porém, o zapatismo tem uma autonomia limitada, porque abrange uma parte muito pequena do país e não impede que o poder central refreie, política e militarmente, os avanços zapatistas (LEMOINE, 2007).
} 
lutam "por mudanças nas relações de poder/sociais e com o Estado" (PALOMINO, 2006, p. 332) $)^{12}$.

Essa luta é visível nos diferentes movimentos que compõem o caso argentino. Os clubes de troca surgem em 1995, num contexto de aumento do desemprego. Os piquetes, que emergem em 1997, são utilizados por organizações de desempregados para demandar subsídios ao governo. As empresas recuperadas surgem entre 1996 e 1998, em nome da manutenção de postos de trabalho e de mudanças no regime de propriedade. As assembléias de bairro surgem a partir da crise institucional de dezembro de 2001, para reivindicar mudanças no sistema político.

Os trabalhadores de empresas recuperadas questionam, de formas diferenciadas, o direito de propriedade. O objetivo comum a todos os casos é, através da recuperação das empresas, manter a fonte de trabalho, de modo a assegurar a subsistência de seus membros. Mas a maneira de fazê-lo é distinta: alguns demandam ao governo um novo regime jurídico (mediante a reforma da lei de falências), a fim de ter proteção legal; outros constituem-se como cooperativas; e outros demandam a estatização sob controle operário.

As assembléias de bairro constituem uma nova forma de "apropriação do espaço urbano" (PALOMINO, 2006, p. 324) e buscam ser autônomas e independentes em relação aos partidos políticos. Promovem diversas atividades, como merenderos e comedores, centros de ajuda escolar, atividades culturais, ocupações para os desempregados, e implementam mecanismos para democratizar o processo decisório (como a rotatividade de coordenações, decisões tomadas por consenso e não por voto).

A política está presente inclusive nos movimentos étnicos, que têm como objetivos a "redefinição da questão nacional dos atuais Estados e a autonomia territorial das nacionalidades dominadas"

\footnotetext{
12 Conforme outros autores, os movimentos sociais desempenham um papel crítico na luta política na $A L$, que se dá em torno dos parâmetros da democracia e da própria definição da arena política, compreendendo "seus participantes, instituições, processos, agenda, campo de ação" (ALVAREZ, DAGNINO e ESCOBAR, 2000, p. 15).
} 
(QUIJANO, 2004, p. 78). Observa-se, aqui, um entrecruzamento de demandas. O movimento equatoriano, por exemplo, articula um projeto nacional (como a proposta de plurinacionalidade do Estado), a uma identidade étnica.

Os indígenas viam o movimento social não como complemento à democracia, mas como questionamento da democracia existente, como forma de disputar a hegemonia na construção de um novo Estado, de redefinir as regras do jogo político. Concebem a proposta de um Estado plurinacional, que se baseia em: "reforma jurídica sob condições de pluralismo jurídico, direitos coletivos, reconhecimento dos territórios ancestrais sob a figura das circunscrições territoriais, reconhecimento das instituições econômicas ancestrais etc" (DÁVALOS, 2004, p. 187). Estabelecem uma política de alianças como outros setores sociais, com quem se unem para deter a privatização da seguridade social, na tentativa de resistir à modernização neoliberal.

Nesse processo, porém, os indígenas constituem organismos para atuar no interior do sistema político, como o movimento Pachakutik no Equador, "criado com o objetivo de levar ao interior do sistema de representação política a discussão sobre a plurinacionalidade" (DÁVALOS, 2004, p. 189); o MAS e o MIP na Bolívia.

Todavia, a institucionalização produz paradoxos: de um lado, tem um potencial transformador; de outro, apresenta limites. A participação do movimento Pachakutik da coalizão indígena-militar elegeu Lucio Gutiérrez em 2002 e, posteriormente, em seu governo fez com que o movimento adotasse uma estratégia dual, articulando a luta institucional à não institucional (RAMÍREZ, 2003). A presença marginal do movimento no governo e sua incapacidade de alterar a agenda neoliberal levaram à deterioração e à ruptura da aliança, após 7 meses. Embora tenha resistido a medidas governamentais, como o aumento do preço do gás, "o movimento político Pachakutik é pego em suas próprias contradições: deve questionar o sistema político desde dentro, mas ao participar finalmente o legitima" (DÁVALOS, 2004, p. 190). Isso evidencia os limites do potencial transformador dessa forma de 
participação, que se dá com determinados aliados e numa determinada conjuntura ${ }^{13}$.

Esse risco também está presente no movimento dos piqueteiros, que se dividem entre os que buscam intervenção no sistema político formal, seja diretamente, através de organizações próprias, ou através dos partidos tradicionais, e os que se opõem a ele. Os primeiros geralmente fazem a intermediação entre os subsídios estatais (como os planos sociais), aos seus membros. Outros resistem a isso (PALOMINO, 2006).

\section{Considerações finais}

A novidade desses movimentos não reside em seu sujeito, já que indígenas se manifestaram em outros momentos históricos, assim como camponeses e desempregados. A novidade também não reside em suas formas de luta ou em suas demandas, já que piquetes e barricadas são historicamente empregados pelo movimento operário. A novidade se deve à conjunção de todos esses elementos numa nova conjuntura, marcada pelo neoliberalismo.

As reivindicações e formas de ação dos movimentos aqui mencionados revelam um conteúdo político variável. A despeito das críticas às instituições políticas existentes, das demandas por autonomia, não se trata de se opor ao âmbito organizativo, nem mesmo de recusar as relações com o Estado. Verificam-se desde a criação de novas organizações e práticas políticas, até demandas que, muitas vezes, passam pelo Estado (como financiamento público, mudanças na legislação - seja uma nova lei de falências, um novo regime jurídico para as empresas, ou do reconhecimento das autonomias indígenas).

Por fim, os conflitos sociais que conduziram a esses movimentos podem ser lidos à luz do pertencimento de classe. Nesse sentido, há uma articulação entre identidades étnicas e ocupacionais e condição de classe. A despeito das diferentes classes e identidades envolvidas, são

${ }^{13}$ A participação também pode ser discutida num outro registro, como forma de combater as instituições existentes, a exemplo das experiências impulsionadas pelo governo Chávez que, não obstante o fato de ocupar o poder central, incentiva a participação popular, nas missões e conselhos comunais, buscando articular a conquista do poder de Estado às mudanças na sociedade civil. 
movimentos de classes trabalhadoras (consideradas em sentido amplo, a fim de incluir as classes médias e os camponeses), que têm em comum o fato de partilhar uma ideologia antineoliberal.

Andréia Galvão é doutora em Ciências Sociais e mestre em Ciência Política pela Universidade Estadual de Campinas (UNICAMP), professora de Sociologia da Unifesp/Guarulhos.

E-mail: andreia.galvao@unifesp.br

\section{Referências:}

ALMEIDA, Lúcio Flávio Rodrigues de. Lutas sociais e questões nacionais na América Latina: algumas reflexões. Lutas Sociais, São Paulo, n. $17 / 18$, p. $64-77,1^{\circ}$ sem. 2006/ $2^{\circ}$ sem. 2007.

ALVAREZ, Sonia; DAGNINO, Evelina; ESCOBAR, Arturo. O cultural e o político nos movimentos sociais latino-americanos. In: (Org.). Cultura e política nos movimentos sociais latino-americanos: novas leituras. Belo Horizonte: Ed. UFMG, 2000. p. 15-57.

BORÓN, Atilio A. A selva e a polis: interrogações em torno da teoria política do zapatismo. In: . Filosofia Política Marxista. São Paulo:

Cortez, 2003. p. 203-230.

CHESNAIS, François; DIVÈS, Jean-Philippe. L"argentinazo". In: iQue se vayan todos! Le peuple d'Argentine se soulève. Paris: Nautilus, 2002. p. 31-63.

COLETTI, Claudinei. Ascensão e refluxo do MST e da luta pela terra na década neoliberal. Idéias, Campinas, n. 9, p. 49-104, 2002.

DÁVALOS, Pablo. Movimento indígena, democracia, Estado y plurinacionalidad en Equador. Revista Venezolana de Economia y Ciencias Sociales, Caracas, v. 10, n. 1, p. 175-202, jan.-abr. 2004.

DO ALTO, Hervé. De la Révolution Nationale à la victoire d'Evo Morales. Retour sur un demi-siècle de luttes em Bolivie populaire (1952-2007). Actuel Marx - Dossier L'Amérique Latine en lutte, hier \& aujourd'hui, Paris, n. 42, p. 84-96, $2^{\circ}$ sem. 2007.

EDER, Klaus. A classe social tem importância no estudo dos movimentos sociais? Uma teoria do radicalismo da classe média. Revista Brasileira de Ciências Sociais, São Paulo, v. 16, n. 46, p. 5-27, jun. 2001. 
FRAZER, Nancy. Da redistribuição ao reconhecimento? Dilemas da justiça na era pós-socialista. In: SOUZA, Jessé (Org.). Democracia hoje: novos desafios para a teoria democrática contemporânea. Brasília: Ed. UnB, 2001. p. 365-86.

GÁNDARA, Miguel Álvarez. Chiapas: nuevos movimientos sociales y nuevo tipo de conflictos. In: SEOANE, José. Movimientos sociales y conflicto en América Latina. Buenos Aires: CLACSO, 2004. p. 103-125.

GOGOL, Eugene. La bataille d'Oaxaca: répression et résistance révolutionnaire. Actuel Marx - Dossier L'Amérique Latine en lutte hier \& aujourd'hui, Paris, n. 42, p. 59-70, 2 sem. 2007.

HOLLOWAY, John. Mudar o Mundo sem tomar o poder. São Paulo: Contraponto, 2003.

HONNETH, Axel. Luta por reconhecimento. São Paulo: Ed. 34, 2003.

LEMOINE, Maurice. Le progress des gauches en Amérique Latine: gouvernements, mouvements sociaux et luttes indigènes. Actuel Marx Dossier L'Amérique Latine en lutte, hier \& aujourd'hui, Paris, n. 42, p. 111-125, $2^{\circ}$ sem. 2007.

MELUCCI, A. The new social movements: a theoretical approach. Social Science Information, Londres, n. 19, p. 199-226, mai. 1980.

OFFE, Claus. New social movements: challenging the boundaries of institutional politics. Social Research, New York, v. 52, n. 4, p. 817-67, winter 1985.

PALOMINO, Héctor et al. A política e o político nos movimentos sociais na Argentina. In: DAGNINO, Evelina; OLVERA, Alberto J.; PANFICHI, Aldo (Org.). A disputa pela construção democrática na América Latina. Rio de Janeiro: Paz e Terra, 2006. p. 309-342.

QUIJANO, Aníbal. El laberinto de América Latina: ¿ hay otras salidas? Revista Venezolana de Economia y Ciencias Sociales, Caracas, v. 10, n. 1, p. 75-97, jan. abr. 2004.

RAMÍREZ GALLEGOS, Franklin. El paso del movimiento indio y Pachakutik por el poder. Revista del OSAL, Buenos Aires, n. 11, p. 4152, mai.-ago. 2003.

REGALSKY, Pablo. Bolívia na encruzilhada: o governo Morales e a política indígena. Outubro, São Paulo, n. 15, p. 45-78, $1^{\circ}$ sem. 2007.

SALLUM JR., Brasilio. Classes, cultura e ação coletiva. Lua Nova, São Paulo, 65, p. 11-42, mai.- ago. 2005. 
SANJINÉS, Javier. Movimientos sociales y cambio politico en Bolívia. Revista Venezolana de Economia y Ciencias Sociales, Caracas, v. 10, n. 1, p. 203-218, jan.-abr. 2004.

STEFANONI, Pablo. Siete preguntas y siete respuestas sobre la Bolivia de Evo Morales. Nueva Sociedad, Buenos Aires, n. 209, p. 46-65, mai.jun. 2007.

TATAGIBA, Luciana. Movimentos sociais e sistema político: uma análise da literatura. In: ENCONTRO DA ASSOCIAÇÃO BRASILEIRA DE CIÊNCIA POLÍTICA, 6, 2008. Campinas. Banco de Papers. Campinas: ABCP, 2008. Disponível em: <http://www. cienciapolitica.org.br/abcp/index2.html>. Acesso em: 02 ago. 2008.

TARROW, Sidney. Power in movement. Social movements, collective action and politics. Cambridge: Cambridge University Press, 1994.

TOURAINE, Alain. The study of social movements. Social Research, New York, v. 52, n. 4, p. 749-87, winter 1985. 